\title{
Oxidation resistance and thermal stability of a $\beta$-solidified $\gamma$-TiAl based alloy after nitrogen ion implantation
}

\author{
D.O. Panov ${ }^{a}$, V.S. Sokolovsky ${ }^{\mathrm{a}, *}$, N.D. Stepanov ${ }^{\mathrm{a}}$, S.V. Zherebtsov ${ }^{\mathrm{a}}$, P.V. Panin ${ }^{\mathrm{b}}$, N. \\ A. Nochovnaya ${ }^{b}$, G.A. Salishchev ${ }^{a}$ \\ ${ }^{a}$ Belgorod State University, 85 Pobeda Str., 308015, Belgorod, Russian Federation \\ ${ }^{\mathrm{b}}$ Federal State Unitary Enterprise "All-Russian Scientific Research Institute of Aviation Materials”, 17 Radio Str., 105005, Moscow, Russian Federation
}

\section{A R T I C L E I N F O}

\section{Keywords:}

A. Intermetallics

B. Ion implantation

B. AES

B. TEM

C. Oxidation

C. Hardening

\begin{abstract}
A B S T R A C T
Oxidation behavior and thermal stability of a $\beta$-solidifying $\gamma$-TiAl alloy after plasma source nitrogen ion implantation were studied. Nano-sized $\mathrm{TiN}, \mathrm{Ti}_{2} \mathrm{~N}, \mathrm{Ti}_{3} \mathrm{AlN}$, and $\mathrm{Ti}_{3} \mathrm{Al}_{2} \mathrm{~N}_{2}$ particles were found in the modified layer. The microhardness of the modified layer was 2.5 times higher than that of the as-cast condition. Nitrogen ion implantation increased the oxidation resistance significantly in comparison to the as-cast condition. Thin inner and outer $\mathrm{TiO}_{2}$, dense protective $\mathrm{Al}_{2} \mathrm{O}_{3}$ and fine-grained mixed $\mathrm{Al}_{2} \mathrm{O}_{3}+\mathrm{TiO}_{2}$ layers were found on the surface after oxidation. The effect of nitrogen ion implantation on phase stability and oxidation mechanisms is analyzed.
\end{abstract}

\section{Introduction}

$\beta$-solidified gamma titanium aluminide ( $\gamma$-TiAl) based alloys are currently considered as one of the most attractive light-weight hightemperature structural materials due to their low density, high specific strength, superior creep resistance, and good oxidation resistance [1-5]. The replacement of high-density Ni-based superalloys by the $\gamma$-TiAl based alloys in aircraft or automobile engines is a promising way to decrease fuel consumption, noise level and $\mathrm{CO}_{2}$ and $\mathrm{NO}_{\mathrm{x}}$ emission [4].

Alloys comprising $42-44$ at.\% of $\mathrm{Al}$ solidify through the $\beta$-phase area without the $\mathrm{L}+\beta \rightarrow \alpha$ peritectic transformation and are called $\beta$-solidified $\gamma$-TiAl alloys. In these alloys fine-grained structures with a relatively soft texture are observed in comparison with those in conventional (or peritectic-solidified) $\gamma$-TiAl $[4,5]$. Microstructure of the as-cast $\beta$-solidified $\gamma$-TiAl based alloys usually consists of colonies of a lamellar $\gamma$ (TiAl) and $\alpha_{2}\left(\mathrm{Ti}_{3} \mathrm{Al}\right)$ intermetallic ordered phases which form in prior $\alpha$-grains.

Meanwhile the usage of the $\gamma$-TiAl based alloys at high temperatures requires additional treatment to protect them from oxidation because the oxidation rate of these alloys accelerates rapidly above $600^{\circ} \mathrm{C}[1,6$, 7]. It is well established that a pure alumina $\left(\mathrm{Al}_{2} \mathrm{O}_{3}\right)$ layer does not form on the unprotected surface of the $\gamma$-TiAl based alloys in an oxidizing atmosphere at elevated temperatures $[8,9]$. The only $\mathrm{Al}_{2} \mathrm{O}_{3}$-former is the $\alpha_{2}\left(\mathrm{Ti}_{3} \mathrm{Al}\right)$ phase, while the $\gamma(\mathrm{TiAl})$ phase promotes the rutile $\left(\mathrm{TiO}_{2}\right)$ formation. Growth of $\mathrm{TiO}_{2}$ grains in the $\mathrm{Al}_{2} \mathrm{O}_{3}$ layer leads to the formation of micropores and cracks. In addition, an adverse transition $\mathrm{Ti}_{3} \mathrm{Al}$ phase layer can be observed underneath [10-12].

Some improvement of the $\gamma$-TiAl based alloys oxidation resistance can be associated with the suppression of $\mathrm{TiO}_{2}$ formation using either bulk alloying or surface modification [1]. Microstructure [13], surface finish [14], and environment $[15,16]$ have also a pronounced effect on the oxidation rate. For instance, the appearance and coarsening of the $\alpha_{2}$ phase particles promote oxidation dramatically $[9,13]$. An increase in the concentration of $\mathrm{Al}$ [17], W [18], Y [19], Si or Nb [20] enhances the oxidation resistance. For example, a high content of $\mathrm{Nb}$ in a Ti-45.0Al-7.1 Nb-1.0Cr alloy increased a potential operating temperature up to $850^{\circ} \mathrm{C}$ [7]. At the same time, the addition of refractory elements can induce casting defects and, as a result, decrease mechanical properties [1]. It should be noted that tailoring of the chemical composition to obtain a good combination of oxidation resistance and mechanical properties is a very challenging task [21].

Another approach to improving oxidation resistance is associated with surface modification by ion implantation or coatings. Both approaches have certain advantages; for example, various coatings can be used for protecting against aggressive environment and/or high temperatures [1]. Ion implantation of metallic or non-metallic elements has some obvious benefits associated with low temperatures of the process or the possibility to treat surfaces with non-zero curvature. An increase in the oxidation resistance of $\gamma$-TiAl based alloys due to implantation of

\footnotetext{
* Corresponding author.

E-mail address: sokolovskiy@bsu.edu.ru (V.S. Sokolovsky).
} 
non-metallic ( $\mathrm{F}, \mathrm{I}$, and $\mathrm{Cl}$ ) or metallic ions ( $\mathrm{Nb}, \mathrm{Al}, \mathrm{Si}$, and $\mathrm{Mo}$ ) was earlier reported in [22-24].

However, nitrogen ion implantation did not necessarily result in an improvement of oxidation resistance [25-27] in spite of a significant increase in hardness and wear resistance of the surface layer [28,29]. Nitrogen ion implantation with relatively high ion energy $-50-140 \mathrm{keV}$ has been well studied in conventional $\gamma$-TiAl [25-27]. In contrast, the application of lower ion energies during chlorine ion implantation can result in a significant increment of oxidation resistant [11]. The lower ion energies can result in a higher concentration of an implanted element at the same radiation dose $[30,31]$ despite a decrement in the modified layer depth. In addition, a lower density of defects introduced during processing retards diffusion and makes the surface structure more stable $[32,33]$. On the other hand, structure and mechanical properties of the modified surface may be changed during annealing or operation at elevated temperatures [34]. For example, some variation in the volume fraction and crystal structure of nitrides can be attained [25]. Thus, the present work aims to study the oxidation behavior and thermal stability of the $\beta$-solidifying $\gamma$-TiAl alloy after plasma source nitrogen ion implantation with relatively low ion energy $(\sim 40 \mathrm{keV})$.

\section{Experimental procedures}

The $\beta$-solidifying $\gamma$-TiAl alloy with the measured chemical composition Ti-43.2Al-1.9V-1.1 Nb-1.0Zr-0.2Gd-0.2B (at.\%) was used in this study. Ingots of the alloy were produced by multiple vacuum-arc melting [35].

Flat samples $\left(20 \times 20 \times 2 \mathrm{~mm}^{3}\right)$ which were cut from the ingots using a Sodick AQ300 L wire electrical discharge machine. The samples surface was ground and then mechanically polished using an OP-S colloidal silicon suspension with an abrasive particle size of $0.04 \mu \mathrm{m}$. The obtained samples were then subjected to plasma source ion implantation at room temperature at a radiation dose of $10^{17} \mathrm{~cm}^{-2}$ and an energy of $40 \mathrm{keV}$ in a vacuum chamber with a pressure in the range $10^{-4}-10^{-5} \mathrm{~Pa}$. Expected heating of the samples during implantation did not exceed $400^{\circ} \mathrm{C}$. The dwell time during implantation was $4 \mathrm{~h}$.

Annealing after ion implantation was performed at 550 or $750{ }^{\circ} \mathrm{C}$ for 1,10 , or $100 \mathrm{~h}$ in a Nabertherm furnace (LT 5/12/P320) with subsequent furnace cooling. To prevent oxidation during annealing, the samples were sealed in quartz tubes filled with argon.

Oxidation resistance tests were performed in a dry air atmosphere using the Nabertherm furnace. Before the testing, the surface of the samples was subjected to ultrasonic cleaning in isopropyl alcohol; then the weight of the samples was measured using HR-200 analytical scales with an accuracy of $0.0001 \mathrm{~g}$. After that, the samples were soaked for $24 \mathrm{~h}$ at $800^{\circ} \mathrm{C}$ and air cooled at the rate of $\sim 3^{\circ} \mathrm{C} / \mathrm{s}$. The heat-treated samples were weighed and then placed again into the pre-heated furnace. The number of such cycles during the oxidation resistance tests varied from 1 to 5 , and the total dwell time at $800^{\circ} \mathrm{C}$ was 24,48 , 72,96 , or $120 \mathrm{~h}$ for $1,2,3,4$ or 5 cycles, respectively.

The chemical composition and surface microhardness after nitrogen ion implantation were studied using a so-called beveled sample with a polished surface inclined $\sim 5^{\circ}$ from the initial specimen surface to increase the apparent thickness of the modified layer. The chemical composition after ion implantation was analyzed using a JEOL JAMP$9500 \mathrm{~F}$ ultra-high resolution Auger scanning electron spectrometer with an accelerating voltage of $10 \mathrm{kV}$ in a high vacuum medium $\left(10^{-6} \mathrm{~Pa}\right)$ after ion surface cleaning directly in the device chamber. The Vickers microhardness was measured using a Wolpert 402MVD semi-automatic hardness tester equipped with a diamond pyramid indenter with a base angle of $136^{\circ}$; a load and a dwell time were $10 \mathrm{~g}$, and $15 \mathrm{~s}$, respectively.

$\mathrm{X}$-ray diffraction analysis (XRD) was conducted using a Rigaku Ultima IV diffractometer and $C u K_{\alpha}$ radiation. Scanning was performed in the $2 \theta$ interval of $15-120^{\circ}$ with a step of $0.02^{\circ}$. The surface layer after oxidation resistance was examined in the glancing angle geometry; the offset angle $(\omega)$ was $0.25^{\circ}$. The surface layer after ion implantation and subsequent annealing in argon was examined using the standard BraggBrentano geometry.

The microstructure of the alloy was studied using scanning electron microscopy (SEM) and transmission electron microscopy (TEM). Following tapes of samples were tested by SEM: beveled sample with a polished surface inclined $\sim 5^{\circ}$ - for the surface and material structure after nitrogen ion implantation; a cross-section of samples - for structure and element distribution of oxidation scale. The samples were examined using a FEI Quanta 600 electron microscope equipped with a backscattered electron (BSE) and an energy-dispersive X-ray spectroscopy (EDS) detector with an accelerating voltage of $30 \mathrm{kV}$. Thin foils for TEM were obtained by a conventional twinjet electro-polishing using TenuPol-5. The electrolyte consisted of 5\% perchloric acid, $35 \%$ butanol, and $60 \%$ methanol. The modified side of the TEM samples both after ion implantation and after annealing was masked; thus the base material side was electrolytically polished only. The voltage and temperature of the polishing were $27 \mathrm{~V}$ and $30^{\circ} \mathrm{C}$, respectively. The obtained samples were examined using a JEOL JEM-2100 electron microscope with an accelerating voltage of $200 \mathrm{kV}$. The size of nitrides was determined using a Digimizer software on dark-field TEM images.

\section{Results and discussion}

\subsection{As-cast conditions and effect of nitrogen ion implantation}

The following phases were detected in the as-cast program alloy by XRD: TiAl $(\gamma), \mathrm{Ti}_{3} \mathrm{Al}\left(\alpha_{2}\right)$, and $\mathrm{GdAl}_{3}$ (Fig. 1). The microstructure of the alloy mostly consisted of lamellar $\left(\alpha_{2}+\gamma\right)$ colonies (Fig. 2). In addition, light layers of the $\beta$ phase, occasionally containing $\omega$ phase particles, were found at boundaries of the colonies. Globular $\gamma$ phase particles were also detected (Fig. 2a). In addition, $\mathrm{GdAl}_{3}$ and $\mathrm{Gd}_{2} \mathrm{TiO}_{5}$ particles, as well as borides, were observed. The average size of the $\left(\alpha_{2}+\gamma\right)$ colonies was found to be $20 \pm 5 \mu \mathrm{m}$; the average interlamellar spacing in the $\left(\alpha_{2}+\gamma\right)$ colonies was $60 \pm 10 \mathrm{~nm}$ (Fig. 2b). More detailed information on the structure of the as-cast alloy can be found elsewhere [36].

A SEM-BSE image of the modified layer after nitrogen ion implantation is shown in Fig. 2c. The measured depth of the modified layer was $\sim 1 \mu \mathrm{m}$. The modified layer was found to be somewhat lighter in comparison with the base material; the border between the modified layer and the base material resembled a wavy bright line. Overall, SEM observation did not detect significant changes in the microstructure after nitrogen ion implantation. However, XRD analysis revealed the presence of various nitride phases after nitrogen ion implantation, namely: $\mathrm{TiN}, \mathrm{Ti}_{2} \mathrm{~N}, \mathrm{Ti}_{3} \mathrm{AlN}, \mathrm{Ti}_{3} \mathrm{Al}_{2} \mathrm{~N}_{2}$ (Fig. 1).

The local chemical compositions of the modified layer and the base

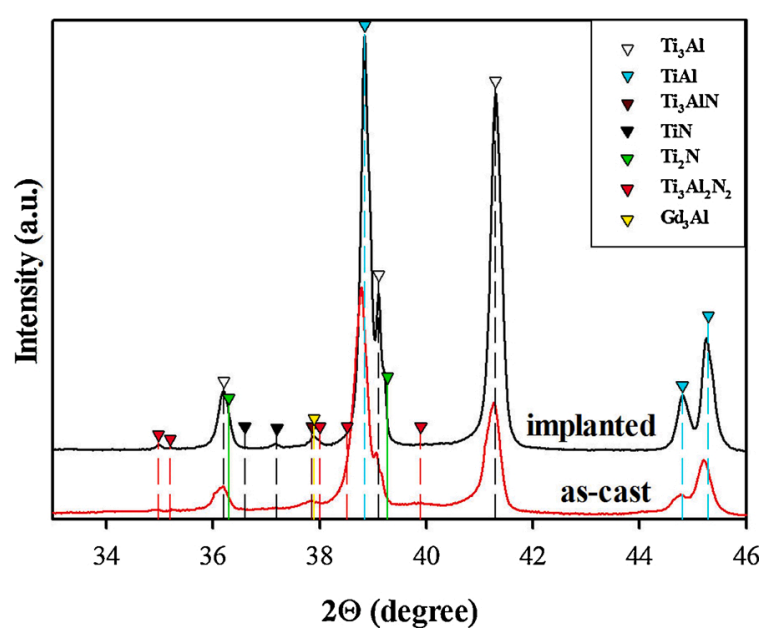

Fig. 1. XRD patterns of the Ti-43.2Al-1.9V-1.1Nb-1.0Zr-0.2Gd-0.2B alloy in the as-cast conditions and after nitrogen ion implantation. 

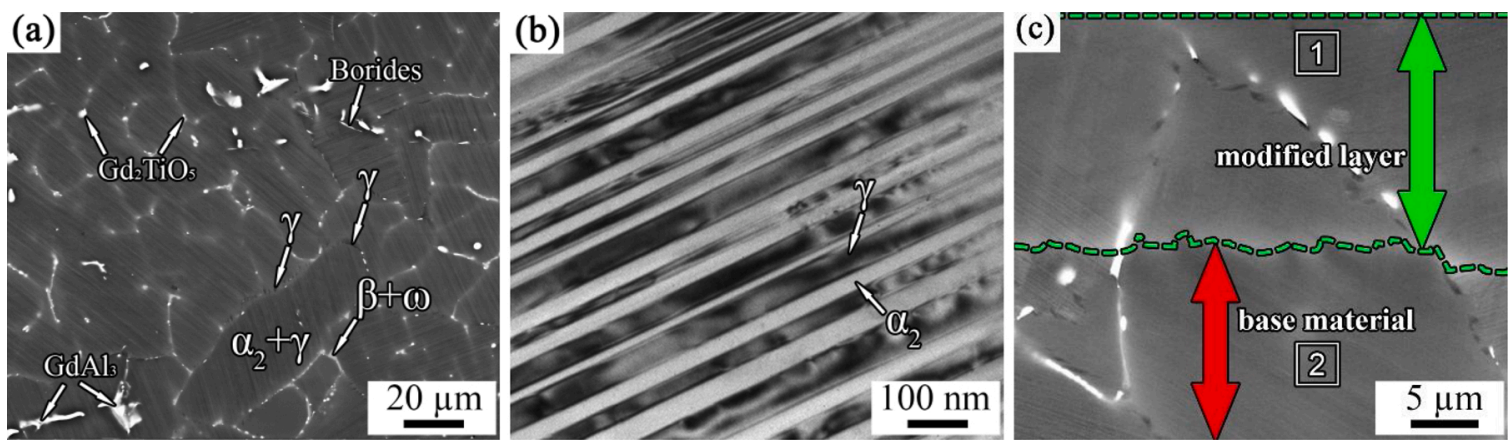

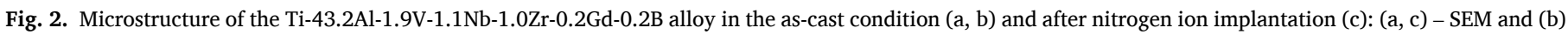

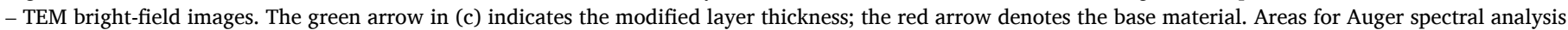

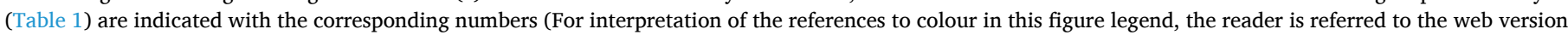
of this article).

material measured by Auger spectroscopy are shown in Table 1 (the corresponding Auger spectra are given in the Supplementary Materials). The content of nitrogen in the modified layer was 50 at.\%. This result is in good agreement with earlier studies of nitrogen ion implantation of dilute titanium alloys [37] or $\gamma$-TiAl based alloys [26,38]. It should be noted that the equilibrium content of nitrogen in the $\alpha_{2}$ phase is above 2.32 at.\% at room temperature [39], reaching 3.5 at.\% at $900{ }^{\circ} \mathrm{C}$ [40]. However, the solubility of nitrogen in the $\gamma$ phase is lower than 0.1 at.\% [41]. Thus, the amount of nitrogen in the modified layer was far beyond the equilibrium solubility in both the $\alpha_{2}$ and $\gamma$ phases. Most likely, an excessive amount of nitrogen results in the precipitation of nitrides [42] that was consistent with the results of XRD analysis (Fig. 1). Evaluation of the N-concentration profile for the applied ion implantation mode using a SRIM-2013 software [43] suggest the depth of the modified layer of $\sim 0.15 \mu \mathrm{m}$ with the maximum concentration at the middle of profile. Some difference with the experimental results could probably be associated with heating during ion implantation up to $400^{\circ} \mathrm{C}$

TEM images (Fig. 3) show that the lamellar structure of the as-cast alloy remained almost unchanged in the modified layer, however an increase in the dislocation density and the formation of some thin deformation twins within both lamellar and globular $\gamma$-phase was observed (Fig. 3a and c); these changes are quite typical of metallic materials subjected to high-energy treatments [29,32]. The high concentration of nitrogen in the modified layer resulted in the formation of nanoparticles with the size of $8-14 \mathrm{~nm}$ of different species of nitrides (TiN, $\mathrm{Ti}_{2} \mathrm{~N}, \mathrm{Ti}_{3} \mathrm{AlN}$, or $\mathrm{Ti}_{3} \mathrm{Al}_{2} \mathrm{~N}_{2}$ ) (Fig. 3 and Table 2). The total volume fraction of all types of nitrides was approximately the same $(\sim 0.2 \%)$ in different phases. An increased concentration of radiation defects and some heating during ion implantation, most likely, increased the kinetic of the nitrogen redistribution and the precipitation formation.

More detailed analysis had revealed that the $\mathrm{Ti}_{2} \mathrm{~N}$ type particles with a spherical or elongated shape (Fig. $3 a$ and $b$ ) were predominantly found inside the $\gamma$ phase lamellae. Although the $\mathrm{Ti}_{2} \mathrm{~N}$ nitrides formation was not observed during reaction of the $\gamma$-TiAl alloy surface with gaseous nitrogen (TiN is usually formed instead $[44,45]$ ), $\mathrm{Ti}_{2} \mathrm{~N}$ was found after ion implantation, probably due to an increased concentration of radiation defects [32]. Results obtained earlier for titanium alloys have suggested that higher ion energy may result in the formation of the $\mathrm{Ti}_{2} \mathrm{~N}$ particles rather than TiN $[46,47]$.

Table 1

Chemical composition of the modified layer and base material (in at.\%) obtained by Auger spectroscopy. Characteristic areas for analysis are shown in Fig. 2c.

\begin{tabular}{|c|c|c|c|c|c|c|c|c|}
\hline$\#$ & Area & $\mathrm{Ti}$ & $\mathrm{Al}$ & $\mathrm{V}$ & $\mathrm{Nb}$ & $\mathrm{Zr}$ & Gd & $\mathrm{N}$ \\
\hline 1 & Modified layer & 25.2 & 23.4 & $<1^{*}$ & $<1$ & $<1$ & $<1$ & 50.0 \\
\hline 2 & Base material & 51.3 & 44.2 & 2.1 & $<1$ & 1.0 & $<1$ & $<1$ \\
\hline
\end{tabular}

" The concentrations below 1.0 at.\% was beneath the detection limit.
Elongated $\mathrm{Ti}_{3} \mathrm{AlN}$ nanoparticles (Fig. 3d) were found within the $\alpha_{2}$ phase lamellae. Other nitrides like TiN and $\mathrm{Ti}_{3} \mathrm{Al}_{2} \mathrm{~N}_{2}$ were observed mostly inside the globular $\gamma$ phase particles at the colony boundaries (Fig. $3 e$ and f). The TiN nitride phase is equilibrium and contains more nitrogen than the other nitrides; therefore, the TiN formation within the $\gamma$ phase, which has the lowest solubility of nitrogen, seems reasonable. The formation of the $\mathrm{Ti}_{3} \mathrm{AlN}$ and $\mathrm{Ti}_{3} \mathrm{Al}_{2} \mathrm{~N}_{2}$ nitrides in the $\gamma$-TiAl based alloy after nitrogen ion implantation is reported for the first time in the present work. However, the possibility of the $\mathrm{Ti}_{3} \mathrm{AlN}$ and $\mathrm{Ti}_{3} \mathrm{Al}_{2} \mathrm{~N}_{2}$ nitrides formation in the Ti-Al-N ternary was previously suggested using thermodynamic modeling [40,48,49].

\subsection{Annealing effect}

The program alloy after ion implantation was annealed at 550 or $750^{\circ} \mathrm{C}$ for $1-100 \mathrm{~h}$ to estimate the stability of the modified layer structure. TEM images and the corresponding XRD patterns of the alloy after annealing are shown in Figs. 4 and 5, respectively. The average sizes of the observed nitrides are summarized in Table 2.

A non-equilibrium condition of the modified layer after high energy treatment should most probably result in some structural transformations upon annealing. The main changes were associated with the nitrides (Table 2): (i) the size of both the $\mathrm{TiN}$ and $\mathrm{Ti}_{3} \mathrm{AlN}$ particles increased noticeably after annealing at both temperatures, however coarser nitrides were found after annealing at $750{ }^{\circ} \mathrm{C}$; (ii) the $\mathrm{Ti}_{3} \mathrm{Al}_{2} \mathrm{~N}_{2}$ particles were stable at $550^{\circ} \mathrm{C}$ and coarsened slightly at $750{ }^{\circ} \mathrm{C}$; (iii) the size of the $\mathrm{Ti}_{2} \mathrm{~N}$ particles decreased gradually with an increase in the annealing time; as a result the $\mathrm{Ti}_{2} \mathrm{~N}$ nitrides disappeared completely after $100 \mathrm{~h}$ annealing at $550^{\circ} \mathrm{C}$ or at $10 \mathrm{~h}$ at $750^{\circ} \mathrm{C}$.

Estimated volume fraction of the different nitrides increased substantially both in the $\alpha_{2}$ phase lamellae (from $\sim 0.2 \%$ to $\sim 0.4 \%$ ) and globular $\gamma$ phase (from $\sim 0.2 \%$ to $\sim 1.2 \%$ ) after annealing at both temperatures $\left(550^{\circ} \mathrm{C}\right.$ and $750^{\circ} \mathrm{C}$ ) for $1 \mathrm{~h}$; further soaking did not result in noticeable changes. The observed increase can, in fact, be related with coagulation of the nitrides that made them more visible for TEM investigations. The fraction of the nitrides in the lamellar $\gamma$ phase was almost unaffected during annealing due to nitrogen diffusion from $\gamma$ towards the $\alpha_{2}$ phase with much higher nitrogen solubility [39-41].

XRD analysis showed similar results (Fig. 4): the intensity of the both (221) and (002) peaks from the $\mathrm{Ti}_{2} \mathrm{~N}$ phase decreased with an increase in soak time to the level comparable with the background after annealing at $550{ }^{\circ} \mathrm{C}$ for $100 \mathrm{~h}$ or at $750{ }^{\circ} \mathrm{C}$ for $10 \mathrm{~h}$. In contrast the (220) maximum of the TiN phase became stronger with the time increasing. This process can be associated with the development of recovery resulting in a reduction in the point defects concentration and, in turn, in a decrease in the stability of the $\mathrm{Ti}_{2} \mathrm{~N}$ nitride particles $[26,44,45,50]$. However, no other evidence of the recovery development was found. Dissolution of $\mathrm{Ti}_{2} \mathrm{~N}$ may intensify diffusion of nitrogen atoms along boundaries and 

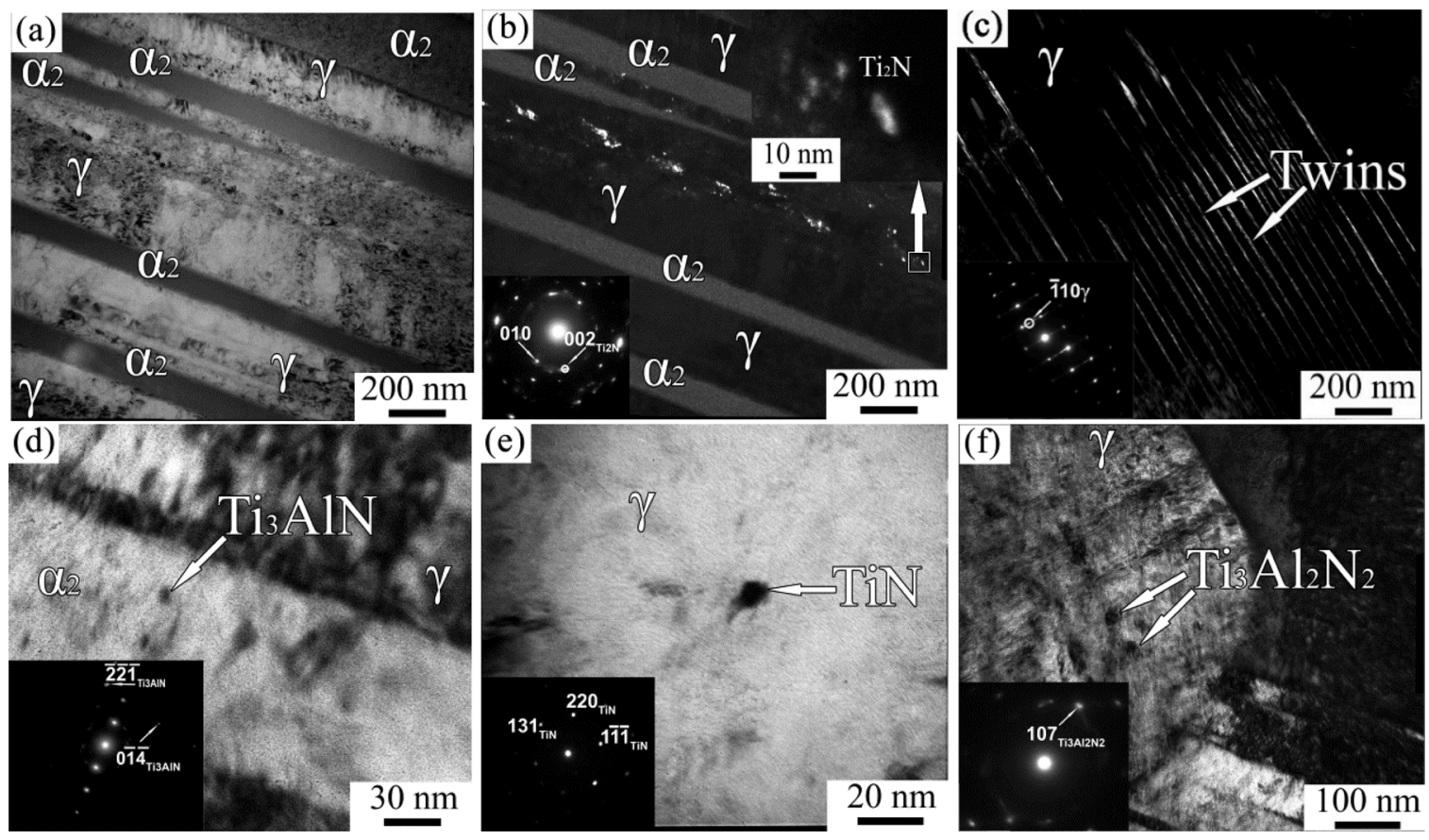

Fig. 3. TEM images of the Ti-43.2Al-1.9V-1.1Nb-1.0Zr-0.2Gd-0.2B alloy after ion implantation: $\mathrm{a}, \mathrm{d}-\mathrm{f}-$ bright-field images and corresponding selected area electron diffraction patterns; $\mathrm{b}$ - dark-field image in the $(002)_{\mathrm{Ti} 2 \mathrm{~N}}$ reflection; $\mathrm{c}$ - dark-field image in the $(\overline{1} 10)_{\gamma}$ reflection.

Table 2

Nitrides particle size in the Ti-43.2Al-1.9V-1.1Nb-1.0Zr-0.2Gd-0.2B alloy after nitrogen ion implantation and subsequent annealing.

\begin{tabular}{|c|c|c|c|c|c|c|c|}
\hline \multirow{4}{*}{ Phase } & \multicolumn{7}{|l|}{ Size of nitrides (nm) } \\
\hline & \multirow{3}{*}{ After nitrogen ion implantation } & \multicolumn{6}{|c|}{ After nitrogen ion implantation and further annealing } \\
\hline & & $550^{\circ} \mathrm{C}$ & $550^{\circ} \mathrm{C}$ & $550{ }^{\circ} \mathrm{C}$ & $750^{\circ} \mathrm{C}$ & $750^{\circ} \mathrm{C}$ & $750^{\circ} \mathrm{C}$ \\
\hline & & $1 \mathrm{~h}$ & $10 \mathrm{~h}$ & $100 \mathrm{~h}$ & $1 \mathrm{~h}$ & $10 \mathrm{~h}$ & $100 \mathrm{~h}$ \\
\hline TiN & $6 \pm 1$ & $6 \pm 2$ & $12 \pm 6$ & $14 \pm 7$ & $12 \pm 15$ & $19 \pm 10$ & $20 \pm 13$ \\
\hline $\mathrm{Ti}_{2} \mathrm{~N}$ & $10 \pm 3$ & $9 \pm 2$ & $7 \pm 2$ & - & $7 \pm 4$ & - & - \\
\hline $\mathrm{Ti}_{3} \mathrm{AlN}$ & $9 \pm 2$ & $14 \pm 4$ & $13 \pm 6$ & $15 \pm 5$ & $11 \pm 3$ & $15 \pm 4$ & $17 \pm 6$ \\
\hline $\mathrm{Ti}_{3} \mathrm{Al}_{2} \mathrm{~N}_{2}$ & $14 \pm 3$ & $14 \pm 6$ & $12 \pm 5$ & $15 \pm 6$ & $12 \pm 4$ & $17 \pm 6$ & $18 \pm 7$ \\
\hline
\end{tabular}

dislocation pipes. As a result, localization of nitrogen and subsequent heterogeneous precipitation of TiN nitrides were expected in those places where transverse twins cross lamellar boundaries (Fig. 5b). In contrast, peaks associated with $\mathrm{Ti}_{3} \mathrm{AlN}$ or $\mathrm{Ti}_{3} \mathrm{Al}_{2} \mathrm{~N}_{2}$ changed little during annealing (Fig. 4). Note that quantitative XRD analysis is impossible due to strong residual stresses in the modified layer [51,52].

The dependence of the surface microhardness on the annealing temperature / duration is shown in Fig. 6. Nitrogen ion implantation resulted in a pronounced increase in the hardness from $410 \mathrm{HV}$ in the ascast state to $1050 \mathrm{HV}$. An increase in surface hardness after ion implantation is obviously associated with the precipitation of nitride nanoparticles, interstitial (by nitrogen atoms) solid solution hardening, a high density of radiation defects and residual stresses $[28,29,38,46$, 52]. A short $(1 \mathrm{~h})$ annealing at $\mathrm{T}=550{ }^{\circ} \mathrm{C}$ did not result in any noticeable changes in the microhardness. However, an increase in time at $550{ }^{\circ} \mathrm{C}$ or in annealing temperature (to $750{ }^{\circ} \mathrm{C}$ ) gradually decreased the microhardness to $950-1000 \mathrm{HV}$. This is most likely caused by a combination of factors, including nitrides coarsening, loss of coherency of nitrides/matrix boundary, diffusion of nitrogen atoms from the surface into the bulk of the material, development of recovery processes, and partial relaxation of residual stresses in the layer [53-55]. It should be noted however, that the interlamellar spacing structure did not noticeably change during annealing at both temperatures (Fig. 5); therefore this factor hardly influenced on hardness.

\subsection{Oxidation resistance}

The oxidation resistance was evaluated during cyclic soaking at $80{ }^{\circ} \mathrm{C}$ for $24 \mathrm{~h}$ ( $1-5$ cycles) with subsequent air cooling. In addition to the oxidizing effects of the hot dry air, this treatment resulted in stresses arising in the surface layer during several heating and cooling due to the thermal expansion coefficients mismatch for various components of the oxidized layer and the base material. In some cases, this can lead to the crack initiation and spallation of oxides [22]. Fig. 7a shows the effect of annealing on the mass gain for the as-cast and nitrogen ion implanted alloy. Two stages can be found in the both cases [10,25,26]. At the first stage, the curves had a parabolic shape which is associated with the formation of a protective oxide layer on the surface. This process seems to be completed during first three cycles, i.e. in $72 \mathrm{~h}$. The protective layer formation led to retardation in the mass gain at the second stage after $3-5$ cycles due to which a significant decrease in the oxidation rate was observed. After 5 cycles, the mass gain of the alloy after ion implantation was $\sim 2 \mathrm{~g} / \mathrm{cm}^{2}$ which was much lower than that in the as-cast alloy $\left(\sim 12 \mathrm{mg} / \mathrm{cm}^{2}\right)$.

The oxidation behavior can be described by a power-law dependence [56]:

$\Delta m=k t^{n}$

where, $\Delta m$ is the mass gain; $t$ is the exposure time in air at the preset temperature; $n$ is the time power; and $k$ is the oxidation reaction rate 
(a)

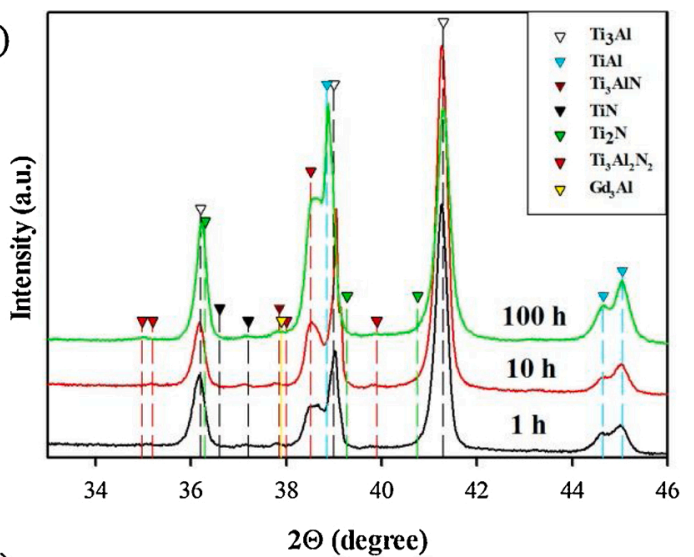

(c)

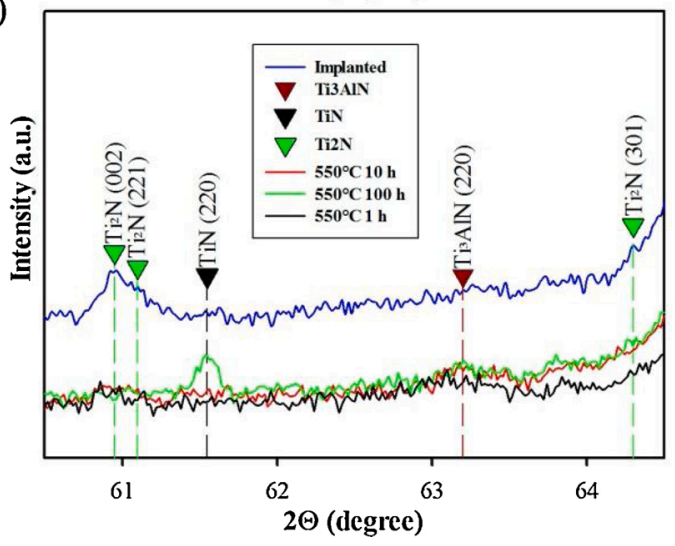

(b)

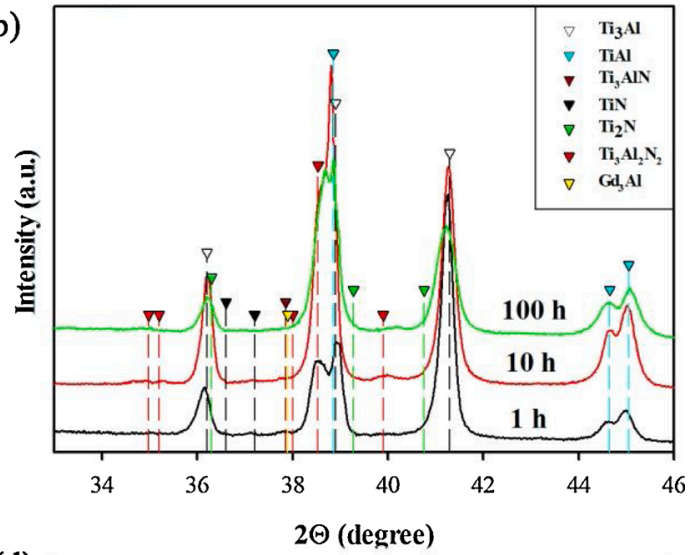

(d)

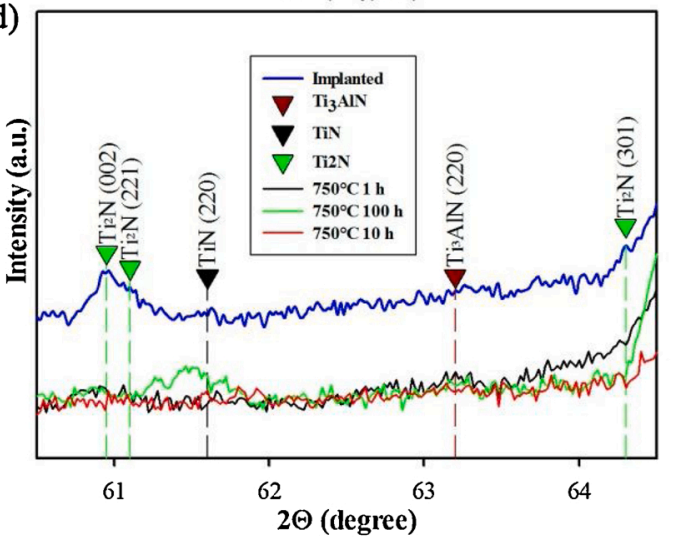

Fig. 4. XRD patterns of the Ti-43.2Al-1.9V-1.1Nb-1.0Zr-0.2Gd-0.2B alloy after nitrogen ion implantation and annealing: a, $\mathrm{c}-$ at a temperature of $550{ }^{\circ} \mathrm{C}$; $\mathrm{b}, \mathrm{d}-\mathrm{at}$ a temperature of $750^{\circ} \mathrm{C}$.
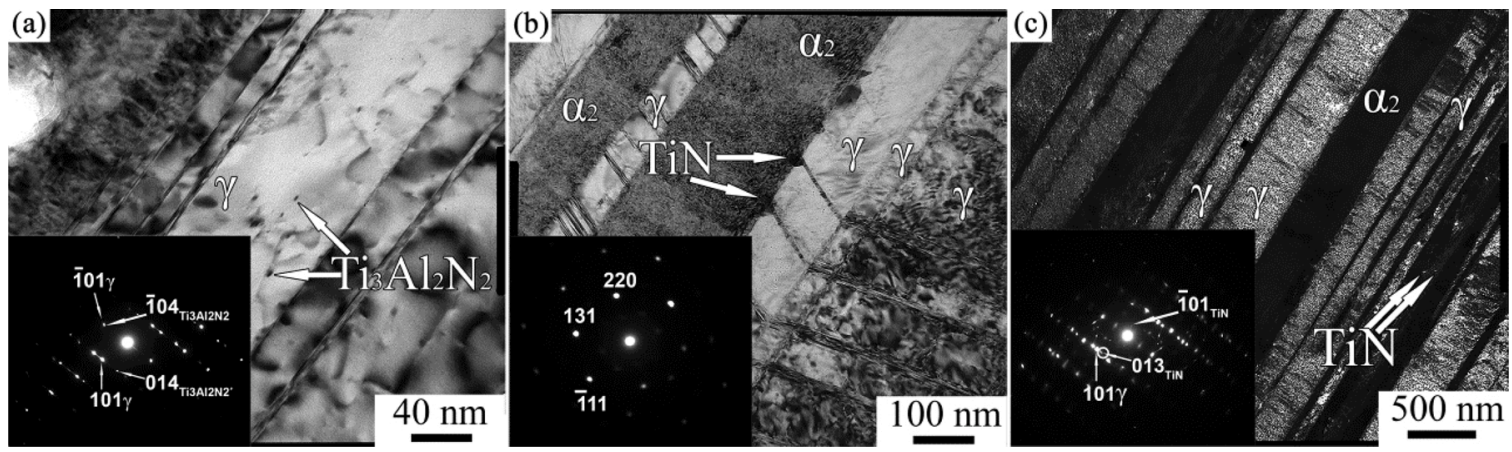

Fig. 5. TEM image of the structure of the Ti- $43.2 \mathrm{Al}-1.9 \mathrm{~V}-1.1 \mathrm{Nb}-1.0 \mathrm{Zr}-0.2 \mathrm{Gd}-0.2 \mathrm{~B}$ alloy after nitrogen ion implantation and annealing: a $-550{ }^{\circ} \mathrm{C}, 10 \mathrm{~h}$; $\mathrm{b}-550{ }^{\circ} \mathrm{C}$, $100 \mathrm{~h} ; \mathrm{c}-750^{\circ} \mathrm{C} .10 \mathrm{~h}$.

constant. The approximation of the experimental data obtained in the current study is shown in Fig. 7b. In the as-cast alloy the values of $\mathrm{n}$ and $\mathrm{k}$ were found to be $n=1.42$ and $k=0.463 \mathrm{mg} \mathrm{cm}^{-2} \mathrm{~s}^{-1} .{ }^{42}$, respectively, for the first stage and $n=0.25, k=0.473 \mathrm{mg} \mathrm{cm}^{-2} \mathrm{~s}^{-0.25}$, respectively, for the second stage. After ion implantation, the respective values were $n=0.61$ and $k=0.001 \mathrm{mg} \mathrm{cm}^{-2} \mathrm{~s}^{-0.61}$ for the first stage, and $n=0.11, k$ $=0.501 \mathrm{mg} \mathrm{cm}^{-2} \mathrm{~s}^{-0.11}$ for the second stage. The following observations were made: (i) the time power $(n)$ reduced drastically after 3 cycles (or $72 \mathrm{~h}$ ) both in the as-cast condition and after ion implantation; (ii) ion implantation resulted in much lower $n$ values at the both stages in comparison with the as-cast state; (iii) the oxidation reaction rate constant $(k)$ was significantly lower after ion implantation at the first stage, but similar values were found at the second stage for both conditions.

Fig. 8 shows XRD patterns obtained from the surface after oxidation resistance tests. Three types of oxides $\left(\mathrm{TiO}_{2}, \mathrm{Al}_{2} \mathrm{O}_{3}\right.$, and $\left.\mathrm{Gd}_{2} \mathrm{O}_{3}\right)$ and two types of nitrides $\left(\mathrm{Ti}_{3} \mathrm{AlN}\right.$ and $\left.\mathrm{Ti}_{3} \mathrm{Al}_{2} \mathrm{~N}_{2}\right)$ were detected in the as-cast and ion implanted conditions. The formation of $\mathrm{TiO}_{2}$ and $\mathrm{Al}_{2} \mathrm{O}_{3}$ on the surface during high-temperature annealing is typical of $\gamma$-TiAl based alloys [21]. The formation of the nitrides in the oxidized layer in the as-cast alloy can be attributed to the presence of nitrogen in the air environment. According to [57], the formation of titanium nitrides in the surface layer prevents the formation of a continuous $\mathrm{Al}_{2} \mathrm{O}_{3}$ layer [58] and promotes spallation along the interface between oxides and nitrides due to mechanical stresses [12].

The oxide layers consisted of $\mathrm{TiO}_{2}$ (gray) and $\mathrm{Al}_{2} \mathrm{O}_{3}$ (black) oxides [19] (Fig. 9). The following layers was observed in the as-cast alloy after 1 oxidation cycle (Fig. 9a): I - outer $\mathrm{TiO}_{2}$ layer, enriched with $\mathrm{Ti}$ and $\mathrm{O}$; II - protective $\mathrm{Al}_{2} \mathrm{O}_{3}$ layer, enriched with $\mathrm{Al}$ and $\mathrm{O}$; III - inner $\mathrm{TiO}_{2}$ layer; IV - mixed $\mathrm{Al}_{2} \mathrm{O}_{3}+\mathrm{TiO}_{2}$ layer; $\mathrm{V}$ - internal oxidation area; VI Al-depleted zone. Due to the presence of some $\mathrm{TiO}_{2}$ particles in the 


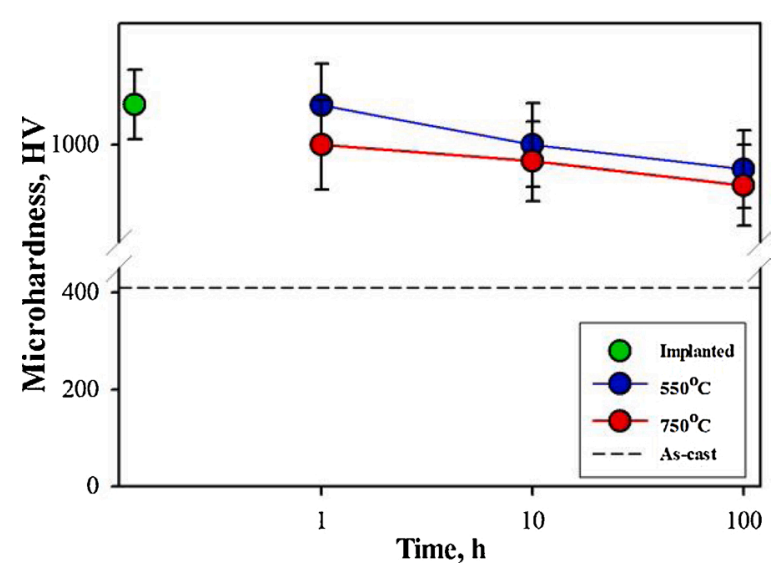

Fig. 6. Surface microhardness of the Ti-43.2Al-1.9V-1.1Nb-1.0Zr-0.2Gd-0.2B alloy after nitrogen ion implantation and during annealing at 550 or $750{ }^{\circ} \mathrm{C}$.

protective $\mathrm{Al}_{2} \mathrm{O}_{3}$ layer the latter was found to be discontinuous. Both the mixed $\mathrm{Al}_{2} \mathrm{O}_{3}+\mathrm{TiO}_{2}$ and $\mathrm{TiO}_{2}$ layers were slightly enriched with $\mathrm{N}$, possibly due to the presence of $\mathrm{Ti}_{3} \mathrm{AlN} / \mathrm{Ti}_{3} \mathrm{Al}_{2} \mathrm{~N}_{2}$ particles and a small amount of nitrogen dissolved in $\mathrm{TiO}_{2}\left(\mathrm{TiO}_{2-\mathrm{x}} \mathrm{N}_{\mathrm{x}}\right)$. The $\mathrm{Al}_{2} \mathrm{O}_{3}$-containing layers were depleted of $\mathrm{Nb}$. An increase in the number of oxidation cycles to 5 resulted in a considerable increase in the depth of both the oxide layer from $18.0 \pm 0.8$ after the first cycle $\mu \mathrm{m}$ to $36.0 \pm 1.2 \mu \mathrm{m}$ and subsurface (which comprises internal oxidation and Al-depleted areas) zone from $1.6 \pm 0.1 \mu \mathrm{m}$ to $7.1 \pm 0.5 \mu \mathrm{m}$ (Fig. 9b). In addition, a loose thin $\mathrm{Al}_{2} \mathrm{O}_{3}$ layer and a a wide $\mathrm{TiO}_{2}$ layer with some $\mathrm{Al}_{2} \mathrm{O}_{3}$ inclusions appeared above the base material. Some cracks and pores were found in the oxide layer, but no signs of spallation were observed.

Meanwhile the microstructural response of the alloy after ion implantation to oxidation tests had some distinct differences (Fig. 9c, d). After 1 cycle, the oxide scale depth was much thinner $-3.5 \pm 0.8 \mu \mathrm{m}$ in the as-cast condition. Moreover, inner $\mathrm{TiO}_{2}$ layer had not almost observed. The internal oxidation area was absent, but Al-depleted area with an depth of $1.0 \pm 0.2 \mu \mathrm{m}$ was formed. Nitrogen was mostly found in the oxide layer. The surface was enriched with $\mathrm{Nb}$. The width of the oxide layer increased to $14.4 \pm 0.9 \mu \mathrm{m}$ after an increase in the number of cycles up to 5 (Fig. 9d). In addition, the following changes were noticed: (i) partial destroying of the protective $\mathrm{Al}_{2} \mathrm{O}_{3}$ layer just below the outer $\mathrm{TiO}_{2}$ layer; (ii) significant growth of both the inner $\mathrm{TiO}_{2}$ and mixed $\mathrm{Al}_{2} \mathrm{O}_{3}+\mathrm{TiO}_{2}$ layers; (iii) appearance of a tiny internal oxidation area; (iv) uniform distribution of $\mathrm{N}$ and $\mathrm{Nb}$ in the oxide layer and base material. Furthermore, a few pores in the inner $\mathrm{TiO}_{2}$ layer were found. The depth of the subsurface zone, comprising internal oxidation and Aldepleted areas, was $2.2 \pm 0.2 \mu \mathrm{m}$.

SEM images of the oxidized surface of the program alloy after annealing at $800^{\circ} \mathrm{C}$ are shown in Fig. 10. The images revealed a considerable difference between the as-cast and the ion implanted conditions. After the first cycle in the as-cast condition the oxidized layer consisted of separate conglomerates of thin needle-shape crystals that were enriched with $\mathrm{Ti}$ and $\mathrm{O}$ and corresponded to the $\mathrm{TiO}_{2}$ phase (Fig. 10a). An increase in the number of cycles resulted in a gradual thickening of the needle-shape crystals (Fig. 10b and c). The crystals also formed a continuous layer already after 3 cycles. A similar surface
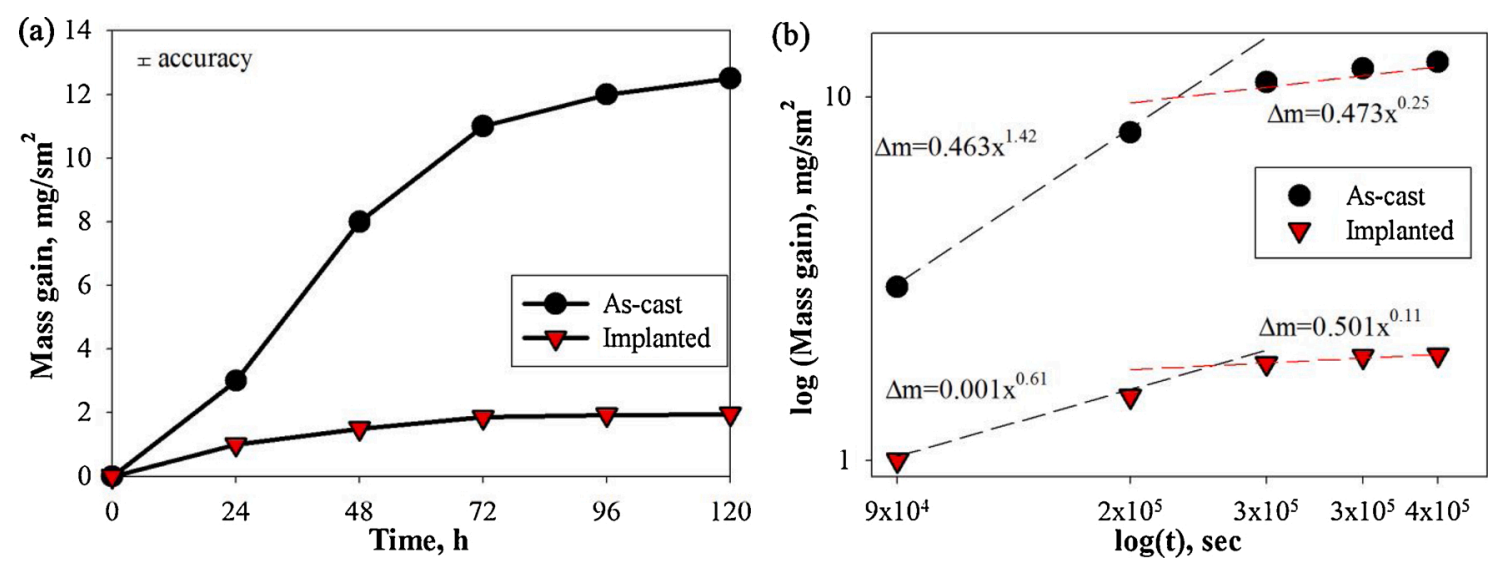

Fig. 7. (a) direct and (b) logarithmic dependence the weight gain of the Ti-43.2Al-1.9V-1.1Nb-1.0Zr-0.2Gd-0.2B alloy in the as-cast condition and after ion implantation on oxidation time in dry air at $800^{\circ} \mathrm{C}$.
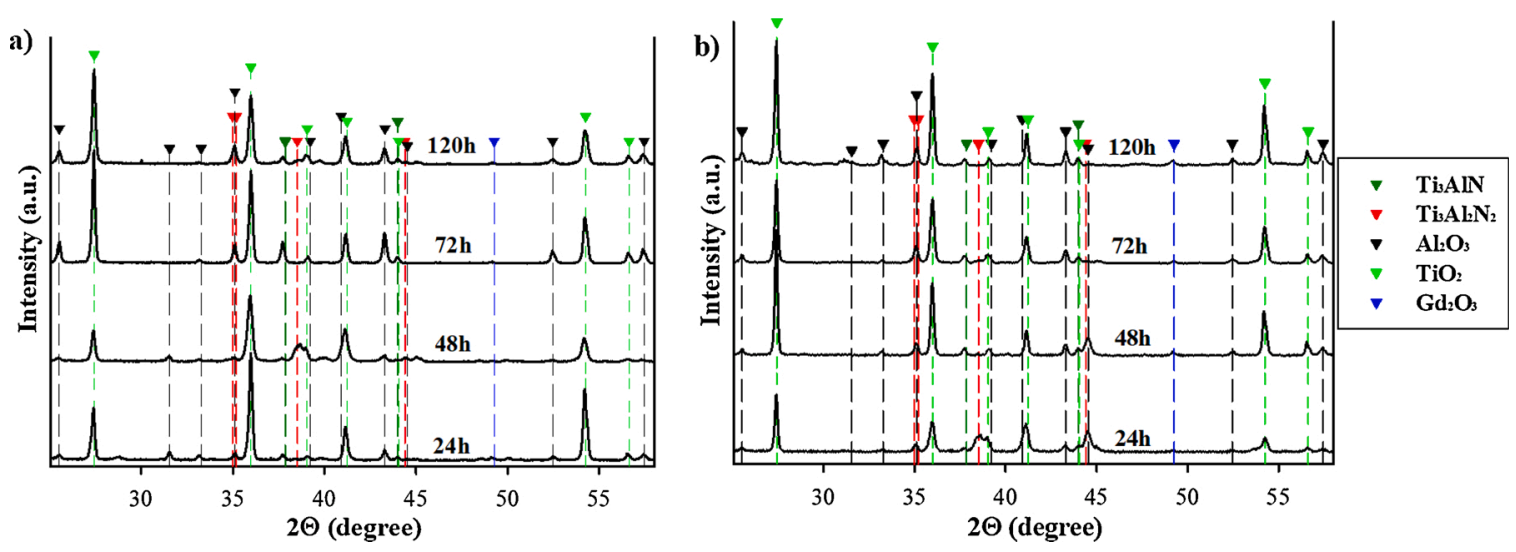

Fig. 8. XRD patterns of the Ti-43.2Al-1.9V-1.1Nb-1.0Zr-0.2Gd-0.2B alloy after various oxidation tests at $800^{\circ} \mathrm{C}$ in the as-cast condition (a) and after nitrogen ion implantation (b). 

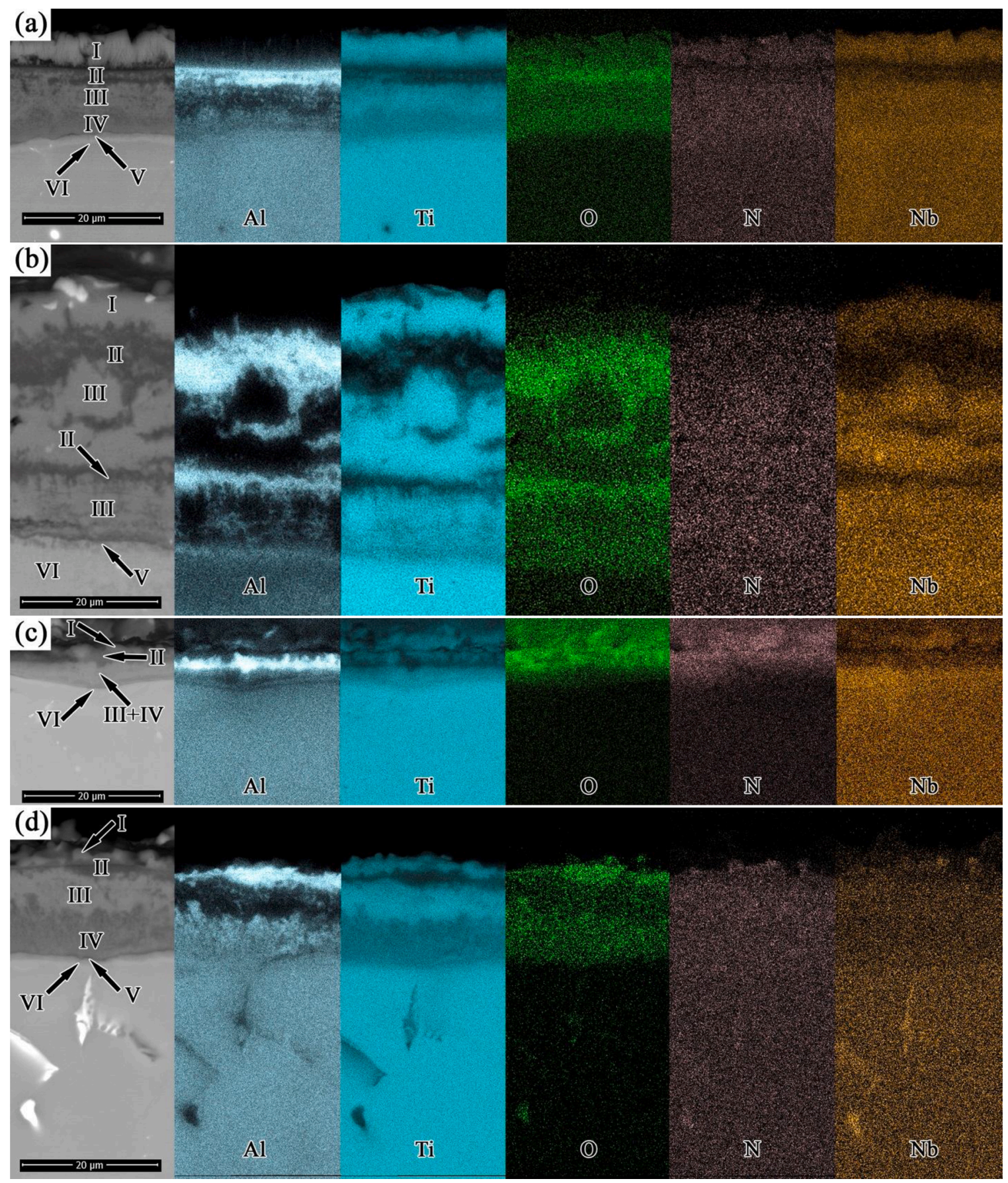

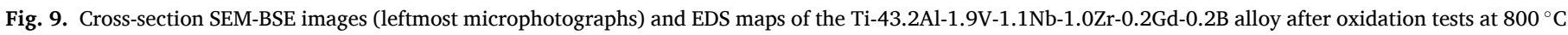

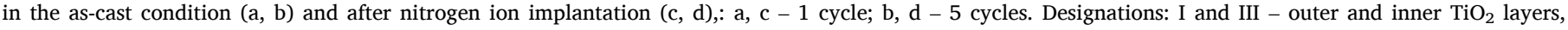
respectively; II - protective $\mathrm{Al}_{2} \mathrm{O}_{3}$ layer; $\mathrm{IV}$ - mixed $\mathrm{Al}_{2} \mathrm{O}_{3}+\mathrm{TiO}_{2}$ layer; $\mathrm{V}$ - internal oxidation area; VI - $\mathrm{Al}$-depleted zone.

structure was observed in $\gamma$-TiAl based alloys after oxidation in humid air [59]. In contrast, coarser flat oxide crystals (most likely the $\mathrm{TiO}_{2}$ phase) formed on the modified surface after the first cycle of the oxidation test (Fig. 10d). At the next cycles, the crystals grown thereby forming a continuous layer which, evidently, can inhibits further surface oxidation (Fig. 10e and f). Such a surface morphology reminds a fine $\mathrm{Al}_{2} \mathrm{O}_{3}$ surface layer obtained after oxidation of an $\mathrm{Al}_{3} \mathrm{Ti}$ alloy in air [10]. No signs of spallation were observed both in the as-cast condition and after nitrogen ion implantation; possibly due to a positive effect of Gd [19].

The formation of a dense protective $\mathrm{Al}_{2} \mathrm{O}_{3}$ layer between the thin outer and inner $\mathrm{TiO}_{2}$ layers of the modified surface at small oxidation time differed significantly from the as-cast alloy behavior and contrasted with the well-known 'halogen effect', where only a dense protective $\mathrm{Al}_{2} \mathrm{O}_{3}$ layer was observed on the modified surface after oxidation [60]. It is known that an increase in the thickness of the outer and inner layers is associated with the outward cation diffusion and inward oxygen anion diffusion, respectively [12]. The formation of a dense protective $\mathrm{Al}_{2} \mathrm{O}_{3}$ layer can effectively inhibit the outward and inward diffusion. Nitrogen ion implantation resulted in titanium nitrides precipitation (Figs. 1 and 2). An increase in activity of aluminum due to depletion of the solid solution by titanium [61] should favor the $\mathrm{Al}_{2} \mathrm{O}_{3}$ layer formation at the initial stages of oxidation and, as a result, in diffusion retardation. In addition, even though the $\mathrm{Nb}$ concentration in the alloy was low, the 

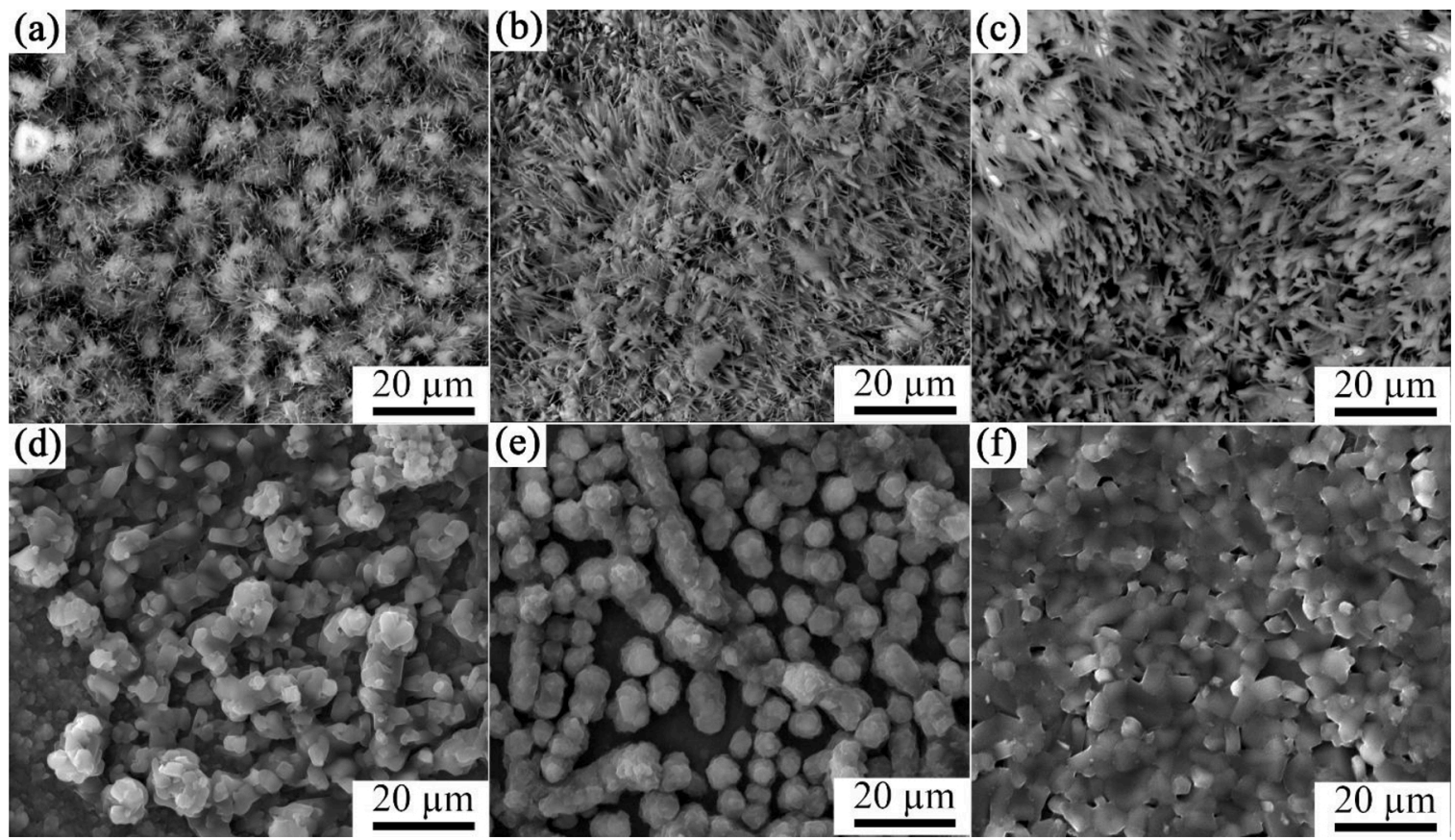

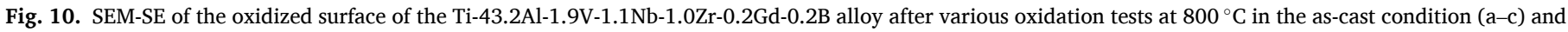
after nitrogen ion implantation $(d-f)$ : $a, d-1$ cycle; $b, e-3$ cycles; $c, f-5$ cycles.

partitioning of $\mathrm{Nb}$ toward surface layer after 1 cycle of the testing can also promote the dense protective $\mathrm{Al}_{2} \mathrm{O}_{3}$ layer formation because of decreased oxygen solubility and increased activity of $\mathrm{Al}$ [13].

On the other hand, according to the SEM-BSE cross-section images and EDS map (Fig. 9c), the nitrogen content was noticeably higher in the $\mathrm{TiO}_{2}$ areas of the oxide layer after ion implantation which can be considered as a modest nitrogen doping. Nitrogen in $\mathrm{TiO}_{2-\mathrm{x}} \mathrm{N}_{\mathrm{x}}$ restricts the vacancy mobility in the oxygen-sublattice [62] that inhibits the inward oxygen diffusion. The latter is associated with the internal oxidation area formation that was quite weak beneath the modified surface.

The use of nitrogen ion implantation with a relatively low ion energy $(\sim 40 \mathrm{keV})$ significantly increased the oxidation resistance of the investigated $\beta$-solidifying Ti-43.2Al-1.9V-1.1Nb-1.0Zr-0.2Gd-0.2B alloy in comparison with that in the as-cast condition. The obtained results are quite unexpected, since a number of studies on $\gamma$-TiAl based alloys after nitrogen ion implantation showed that this treatment does not increase the oxidation resistance, but rather leads to an intensification of the surface degradation process in an oxidizing medium [25,26]. In the mentioned studies, higher energies of nitrogen ions were used during implantation, which probably led to the accumulation of a greater number of radiation defects in the modified layer and, thus, negatively affected both the modified layer stability and oxidation resistance. For instance, ion implantation of phosphorus with high energies lowered the oxidation resistance of a $\mathrm{Ti}-50 \mathrm{Al}$ (at.\%) alloy due to the activation of $\mathrm{Ti}$ atoms diffusion and destruction of the $\mathrm{Al}_{2} \mathrm{O}_{3}$ protective layer [11].

On the other hand, nitrogen coating (obtained via diffusion; i.e. without radiation defects) also reduced the oxidation resistance of a Ti47Al-2Nb-2Cr-0.2Si alloy [61]. In this case the negative effect was associated with the formation of an external TiN layer which transformed into $\mathrm{TiO}_{2}$ in oxygen atmosphere at temperatures above $500{ }^{\circ} \mathrm{C}$ [63]. It should also be mentioned that the effect of nitrogen ion implantation on the oxidation resistance have been studied in $\gamma$-TiAl alloys which showed better oxidation resistance in comparison with the program alloy due to a higher content of $\mathrm{Al}$ [17]. After nitrogen ion implantation, the oxidation resistance of the program alloy is comparable with chlorine- [11,64] or niobium- [65] implanted $\gamma$-TiAl based alloys. In summary, the obtained results show that nitrogen ion implantation under a proper condition can also be considered as a promising way to increase the oxidation resistance of $\gamma$-TiAl based alloys, however, further studies are required to verify the positive effect of nitrogen ion implantation using different alloys and/or oxidation conditions.

\section{Conclusion}

The effect of plasma source nitrogen ion implantation on the structure evolution of the modified layer and the oxidation resistance of the $\beta$-solidifying Ti-43.2Al-1.9V-1.1Nb-1.0Zr-0.2Gd-0.2B alloy was studied. The following conclusions can be drawn.

1 After nitrogen ion implantation the TiN, $\mathrm{Ti}_{2} \mathrm{~N}, \mathrm{Ti}_{3} \mathrm{AlN}$, and $\mathrm{Ti}_{3} \mathrm{Al}_{2} \mathrm{~N}_{2}$ phases are observed in the modified layer. The $\mathrm{Ti}_{2} \mathrm{~N}$ particles predominantly form inside the $\gamma$ phase lamellae, the $\mathrm{Ti}_{3} \mathrm{AlN}$ particles are found within the $\alpha_{2}$ lamellae, while the TiN and $\mathrm{Ti}_{3} \mathrm{Al}_{2} \mathrm{~N}_{2}$ particles are located inside the globular $\gamma$ phase particles. Subsequent annealing at 550 or $750{ }^{\circ} \mathrm{C}$ results in some coarsening of the TiN, $\mathrm{Ti}_{3} \mathrm{AlN}$, and $\mathrm{Ti}_{3} \mathrm{Al}_{2} \mathrm{~N}_{2}$ phase particles, and dissolution the $\mathrm{Ti}_{2} \mathrm{~N}$ phase.

2 The microhardness of the modified layer was found to be $1050 \mathrm{HV}$, which is more than 2.5 times higher than that of the as-cast condition $(410 \mathrm{HV})$. Subsequent annealing at 550 or $750{ }^{\circ} \mathrm{C}$ is accompanied by a gradual decrease in the microhardness to $950-1000 \mathrm{HV}$ with an increase in annealing time to $100 \mathrm{~h}$.

3 Nitrogen ion implantation resulted in a significant increase in the oxidation resistance of the implanted alloy in comparison with the as-cast condition. A positive effect in terms of oxidation resistance is observed after nitrogen ion implantation with an energy of $40 \mathrm{keV}$ and a radiation dose of $10^{17} \mathrm{~cm}^{-2}$. During oxidation of the modified layer a continuous layer is formed, consisting of thin inner and outer $\mathrm{TiO}_{2}$, dense protective $\mathrm{Al}_{2} \mathrm{O}_{3}$ and fine-grained mixed $\mathrm{Al}_{2} \mathrm{O}_{3}+\mathrm{TiO}_{2}$ layers, in contrast to the as-cast condition, wherein a rough layered structure of $\mathrm{TiO}_{2}$ and $\mathrm{Al}_{2} \mathrm{O}_{3}$ with pores and cracks is formed.

\section{CRediT authorship contribution statement}

D.O. Panov: Writing - review \& editing, Validation. V.S. Sokolovsky: Writing - original draft, Methodology, Investigation. N.D. Stepanov: Writing - review \& editing. S.V. Zherebtsov: Writing - review \& 
editing. P.V. Panin: Resources, Methodology. N.A. Nochovnaya: Resources. G.A. Salishchev: Conceptualization, Supervision.

\section{Declaration of Competing Interest}

The author declare that they have no known competing financial interests or personal relationships that could have appeared to influence the work reported in this paper.

\section{Acknowledgements}

The authors gratefully acknowledge the financial support from the Russian Science Foundation Grant no. 19-79-30066. The authors are grateful to the personnel of the Joint Research Center, "Technology and Materials", Belgorod National Research University, for their assistance.

\section{Appendix A. Supplementary data}

Supplementary material related to this article can be found, in the online version, at doi:https://doi.org/10.1016/j.corsci.2020.109003.

\section{References}

[1] F. Appel, J.D.H. Paul, M. Oehring, Gamma Titanium Aluminide Alloys: Science and Technology, Wiley, Weinheim, 2012.

[2] C. Leyens, M. Peters, Titanium and Titanium Alloys, Wiley, Weinheim, 2003.

[3] Y.W. Kim, Intermetallic alloys based on gamma titanium aluminide, Jom. 41 (1989) 24-30, https://doi.org/10.1007/BF03220267.

[4] S. Mayer, P. Erdely, F.D. Fischer, D. Holec, M. Kastenhuber, T. Klein, H. Clemens, Intermetallic $\beta$-solidifying $\gamma$-TiAl based alloys - from fundamental research to application, Adv. Eng. Mater. 19 (2017) 1-27, https://doi.org/10.1002/ adem.201600735.

[5] Y.W. Kim, S.L. Kim, Advances in gammalloy materials-processes-application technology: successes, dilemmas, and future, JOM 70 (2018) 553-560, https://doi. org/10.1007/s11837-018-2747-x.

[6] J.W. Fergus, Review of the effect of alloy composition on the growth rates of scales formed during oxidation of gamma titanium aluminide alloys, Mater. Sci. Eng. A 338 (2002) 108-125, https://doi.org/10.1016/S0921-5093(02)00064-3.

[7] T. Tetsui, S. Ono, Endurance and composition and microstructure effects on endurance of TiAl used in turbochargers, Intermetallics 7 (1999) 689-697, https:// doi.org/10.1016/S0966-9795(98)00085-5.

[8] A. Gil, E. Wallura, H. Grobmeier, W.J. Quadakkers, The influence of cooling rate during alloy casting on the oxidation behavior of TiAI-based intermetallics, J. Mater. Sci. 28 (1993) 5869-5874, https://doi.org/10.1007/BF00365194.

[9] A. Gil, H. Hoven, E. Wallura, W.J. Quadakkers, The effect of microstructure on the oxidation behaviour of TiAl-based intermetallics, Corros. Sci. 34 (1993) 615-630, https://doi.org/10.1016/0010-938X(93)90276-M.

[10] Y. Umakoshi, M. Yamaguchi, T. Sakagami, T. Yamane, Oxidation resistance of intermetallic compounds Al3Ti and TiAl, J. Mater. Sci. 24 (1989) 1599-1603, https://doi.org/10.1007/BF01105677.

[11] G. Schumacher, F. Dettenwanger, M. Schütze, U. Hornauer, E. Richter, E. Wieser, W. Möller, Microalloying effects in the oxidation of TiAl materials, Intermetallics 7 (1999) 1113-1120, https://doi.org/10.1016/S0966-9795(99)00032-1.

[12] S. Becker, A. Rahmel, M. Schorr, M. Schütze, Mechanism of isothermal oxidation of the intel-metallic TiAl and of TiAl alloys, Oxid. Met. 38 (1992) 425-464, https:// doi.org/10.1007/BF00665663.

[13] P. Pérez, J.A. Jiménez, G. Frommeyer, P. Adeva, The influence of the alloy microstructure on the oxidation behavior of Ti-46Al-1Cr-0.2Si alloy, Oxid. Met. 53 (2000) 99-124, https://doi.org/10.1023/A:1004534830767.

[14] J.M. Rakowski, G.H. Meier, F.S. Pettit, F. Dettenwanger, E. Schumann, M. Rühle, The effect of surface preparation on the oxidation behavior of gamma TiA1-base intermetallic alloys, Scr. Mater. 35 (1996) 1417-1422, https://doi.org/10.1016/ S1359-6462(96)00315-6.

[15] N. Zheng, W.J. Quadakkers, A. Gil, H. Nickel, Studies concerning the effect of nitrogen on the oxidation behavior of TiAl-based intermetallics at $900^{\circ} \mathrm{C}$, Oxid. Met. 44 (1995) 477-499, https://doi.org/10.1007/BF01051039.

[16] S. Taniguchi, N. Hongawara, T. Shibata, Influence of water vapour on the isothermal oxidation behaviour of TiAl at high temperatures, Mater. Sci. Eng. A 307 (2001) 107-112, https://doi.org/10.1016/S0921-5093(00)01967-5.

[17] W.J. Quadakkers, P. Schaaf, N. Zheng, A. Gil, E. Wallura, Beneficial and Detrimental Effects of Nitrogen on the Oxidation Behaviour of TiAl-Based Intermetallics, Oxid. Intermet. (2007) 275-287, https://doi.org/10.1002/ 9783527612413.ch19.

[18] D.Y. Seo, T.D. Nguyen, D.B. Lee, Oxidation of powder metallurgy (PM) Ti-48\%Al$2 \% \mathrm{Cr}-2 \% \mathrm{Nb}-(0-1 \%) \mathrm{W}$ alloys between 800 and $1000^{\circ} \mathrm{C}$ in air, Oxid. Met. 74 (2010) 145-156, https://doi.org/10.1007/s11085-010-9203-9.

[19] L.L. Zhao, G.Y. Li, L.Q. Zhang, J.P. Lin, X.P. Song, F. Ye, G.L. Chen, Influence of Y addition on the long time oxidation behaviors of high $\mathrm{Nb}$ containing TiAl alloys at
$900{ }^{\circ} \mathrm{C}$, Intermetallics 18 (2010) 1586-1596, https://doi.org/10.1016/j. intermet.2010.04.012.

[20] J.D. Sunderkötter, H.J. Schmutzler, V.A.C. Haanappel, R. Hofman, W. Glatz, H. Clemens, M.F. Stroosnijder, The high-temperature oxidation behaviour of Ti47Al-2Cr-0.2Si and Ti-48Al-2Cr-2Nb compared with Ti-48Al-2Cr, Intermetallics 5 (1997) 525-534, https://doi.org/10.1016/S0966-9795(97)00025-3.

[21] J. Dai, J. Zhu, C. Chen, F. Weng, High temperature oxidation behavior and research status of modifications on improving high temperature oxidation resistance of titanium alloys and titanium aluminides: a review, J. Alloys. Compd. 685 (2016) 784-798, https://doi.org/10.1016/j.jallcom.2016.06.212.

[22] A. Donchev, M. Schütze, Improving the oxidation resistance of $\gamma$-titanium aluminides by halogen treatment, Mater. Corros. 59 (2008) 489-493, https://doi. org/10.1002/maco.200804132.

[23] X.Y. Li, T.H. Zhang, B.K. Ma, Y.G. Zhang, C.Q. Chen, Influence of post-implantation annealing on the oxidation behavior of $\mathrm{Nb}$ implanted $\gamma$-TiAl based alloy, Nucl. Instr. Methods Phys. Res. Sect. B Beam Interact. Mater. Atoms. 169 (2000) 37-42, https://doi.org/10.1016/S0168-583X(00)00013-6.

[24] S. Taniguchi, K. Uesaki, Y.C. Zhu, Y. Matsumoto, T. Shibata, Influence of implantation of $\mathrm{Al}, \mathrm{Si}, \mathrm{Cr}$ or Mo ions on the oxidation behaviour of TiAl under thermal cycle conditions, Mater. Sci. Eng. A 266 (1999) 267-275, https://doi.org/ 10.1016/s0921-5093(99)00042-8.

[25] L.D. Yu, S. Thongtem, T. Vilaithong, M.J. McNallan, Modification of tribology and high-temperature behavior of Ti-47Al intermetallic alloy nitrided by $\mathrm{N}$ ion implantation, Surf. Coatings Technol. 128-129 (2000) 410-417, https://doi.org/ 10.1016/S0257-8972(00)00643-5.

[26] W. Xi, Y. Yunjie, L. Xianghuai, Z. Shichang, S. Tanaguchi, K. Takahashi, M. Iwaki, Characteristics of the nitrogen ion implanted intermetallic compound TiAl, Nucl. Instrum. Methods Phys. Res. B 80-81 (1993) 250-253, https://doi.org/10.1016/ 0168-583X(93)96117-U.

[27] M. Yoshihara, S. Taniguchi, K. Fujita, The effect of nitrogen ion implantation on the oxidation behavior of TiAl, J. Jpn. I Met. 68 (2004) 468-474, https://doi.org/ 10.2320/jinstmet.68.468.

[28] G.S. Was, Hardness of ion-implanted Ni3Al and TiAl, J. Mater.Res. 6 (8) (1991) 1615-1618, https://doi.org/10.1557/JMR.1991.1615.

[29] J.C. Pivin, Structure and wear resistance of Ti and TiAl surfaces implanted with B, C, N, O, J. Mater. Sci. 25 (1990) 2743-2753, https://doi.org/10.1007/ BF00584874.

[30] P.J. Masset, S. Neve, H.E. Zschau, M. Schütze, Influence of alloy compositions on the halogen effect in TiAI alloys, Mater. Corros. 59 (2008) 609-618, https://doi. org/10.1002/maco.200804145.

[31] M. Schütze, G. Schumacher, F. Dettenwanger, U. Hornauer, E. Richter, E. Wieser, W. Möller, The halogen effect in the oxidation of intermetallic titanium aluminides, Corros. Sci. 44 (2002) 303-318, https://doi.org/10.1016/S0010-938X(01)000622.

[32] X. Zhang, K. Hattar, Y. Chen, L. Shao, J. Li, C. Sun, K. Yu, N. Li, M.L. Taheri, H. Wang, J. Wang, M. Nastasi, Radiation damage in nanostructured materials, Prog. Mater. Sci. 96 (2018) 217-321, https://doi.org/10.1016/j. pmatsci.2018.03.002

[33] M. Poate, G. Foti, D.C. Jacobson, Surface Modification and Alloying by Laser, Ion, and Electron Beams, Plenum Press, New York and London, 1983.

[34] S. Taniguchi, T. Kuwayama, Y.C. Zhu, Y. Matsumoto, T. Shibata, Influence of silicon ion implantation and post-implantation annealing on the oxidation behaviour of TiAl under thermal cycle conditions, Mater. Sci. Eng. A 277 (2000) 229-236, https://doi.org/10.1016/s0921-5093(99)00542-0.

[35] P.V. Panin, A.S. Kochetkov, A.V. Zavodov, E.A. Lukina, Effect of Gd addition on phase composition, structure, and properties of beta-solidifying TiAl-based alloy with $\mathrm{Zr}$ and $\mathrm{Cr}$ content variability, Intermetallics 121 (2020) 106781, https://doi. org/10.1016/j.intermet.2020.106781.

[36] V.S. Sokolovsky, N.D. Stepanov, S.V. Zherebtsov, N.A. Nochovnaya, P.V. Panin, M. A. Zhilyakova, A.A. Popov, G.A. Salishchev, Hot deformation behavior and processing maps of B and Gd containing $\beta$-solidified TiAl based alloy, Intermetallics 94 (2018) 138-151, https://doi.org/10.1016/j.intermet.2018.01.004.

[37] P. Vlcak, F. Cerny, J. Drahokoupil, J. Sepitka, Z. Tolde, The microstructure and surface hardness of Ti6Al4V alloy implanted with nitrogen ions at an elevated temperature, J. Alloys. Compd. 620 (2015) 48-54, https://doi.org/10.1016/j. jallcom.2014.09.125.

[38] K. Saito, T. Matsushima, Nitrogen ion implantation into the intermetallic compound TiAl, Mater. Sci. Eng. A 115 (1989) 355-359, https://doi.org/10.1016/ 0921-5093(89)90703-X.

[39] F. Perdrix, M.F. Trichet, J.L. Bonnentien, M. Cornet, J. Bigot, Influence of nitrogen on the microstructure and mechanical properties of Ti-48Al alloy, Intermetallics 9 (2001) 147-155, https://doi.org/10.1016/S0966-9795(00)00120-5.

[40] N. Durlu, U. Gruber, M.A. Pietzka, H. Schmidt, J.C. Schuster, Phases and phase equilibria in the quaternary system Ti-Cu-Al-N at $850^{\circ} \mathrm{C}$, Zeitschrift Fuer Met. Res. Adv. Tech. 88 (1997) 390-400.

[41] T. Zhang, Z. Wu, R. Hu, F. Zhang, H. Kou, J. Li, Influence of nitrogen on the microstructure and solidification behavior of high Nb containing TiAl alloys, Mater. Des. 103 (2016) 100-105, https://doi.org/10.1016/j.matdes.2016.04.071.

[42] S. Thongtem, C. Boonruang, T. Thongtem, M. McNallan, Nitridation of $\gamma$-TiAl alloys by direct metal-gas reaction at 1000-1300 K, Surf. Interface Anal. 37 (2005) 765-769, https://doi.org/10.1002/sia.2074.

[43] J.F. Ziegler, J.P. Biersak, U. Littmark, in: J.F. Ziegler, J.P. Biersak, U. Littmark (Eds.), The Stopping and Range of Ions in Solids, 1996. New York.

[44] K. Sopunna, T. Thongtem, M. McNallan, S. Thongtem, Surface modification of the $\gamma$-TiAl alloys by the nitridation, Surf. Sci. 566-568 (2004) 810-815, https://doi. org/10.1016/j.susc.2004.06.113. 
[45] K. Sopunna, T. Thongtem, M. McNallan, S. Thongtem, Formation of titanium nitride on $\gamma$-TiAl alloys by direct metal-gas reaction, J. Mater. Sci. 41 (2006) 4654-4662, https://doi.org/10.1007/s10853-006-0030-y.

[46] V. Fouquet, L. Pichon, A. Straboni, M. Drouet, Nitridation of Ti6Al4V by PBII: Study of the nitrogen diffusion and of the nitride growth mechanism, Surf. Coatings Technol. 186 (2004) 34-39, https://doi.org/10.1016/j.surfcoat.2004.04.006.

[47] B. Rauschenbach, K. Hochmuth, Synthesis of compounds by high-fluence nitrogen ion implantation in titanium, Phys. Status Solidi 94 (1986) 833-837, https://doi org/10.1002/pssa.2210940251.

[48] A.S. Bhansali, R. Sinclair, A.E. Morgan, A thermodynamic approach for interpreting metallization layer stability and thin-film reactions involving four elements: application to integrated circuit contact metallurgy, J. Appl. Phys. 68 (1990) 1043-1049, https://doi.org/10.1063/1.346743.

[49] J.C. Schuster, J. Bauer, The ternary system titanium-aluminum-nitrogen, J. Solid State Chem. 53 (1984) 260-265, https://doi.org/10.1016/0022-4596(84)90100-2

[50] D. Manova, J.W. Gerlach, H. Neumann, W. Assmann, S. Mändl, Phase formation in Ti after high fluence/high temperature nitrogen implantation, Nucl. Instr. Methods Phys. Res. Sect. B Beam Interact. Mater. Atoms. 242 (2006) 282-284, https://doi. org/10.1016/j.nimb.2005.08.058.

[51] D.S. Rickerby, A.M. Jones, B.A. Bellamy, X-ray diffraction studies of physically vapour-deposited coatings, Surf. Coatings Technol. 37 (1989) 111-137, https:// doi.org/10.1016/0257-8972(89)90124-2.

[52] S.L.R. Silva, L.O. Kerber, L. Amaral, C.A. Santos, X-ray diffraction measurements of plasma-nitrided Ti - 6Al - 4V, Surf. Coat. Technol. 119 (1999) 342-346.

[53] Rachbauer, S. Massl, E. Stergar, D. Holec, D. Kiener, J. Keckes, J. Patscheider, M. Stiefel, H. Leitner, P.H. Mayrhofer, Decomposition pathways in age hardening of Ti-Al-N films, J. Appl. Phys. 110 (2011), 023515, https://doi.org/10.1063/ 1.3610451.

[54] A.E. Santana, A. Karimia, V.H. Derflinger, A. Schütze, Thermal treatment effects on microstructure and mechanical properties of TiAlN thin films, Tribol. Lett. 17 (November 4) (2004) 689-696, https://doi.org/10.3390/ma9120961.

[55] P.H. Mayrhofer, A. Hörling, L. Karlsson, J. Sjölén, T. Larsson, C. Mitterer, L. Hultman, Self-organized nanostructures in the Ti-Al-N system, Appl. Phys. Lett. 83 (2003) 2049-2051, https://doi.org/10.1063/1.1608464.
[56] O.N. Senkov, S.V. Senkova, D.M. Dimiduk, C. Woodward, D.B. Miracle, Oxidation behavior of a refractory NbCrMo 0.5Ta 0.5TiZr alloy, J. Mater. Sci. 47 (2012) 6522-6534, https://doi.org/10.1007/s10853-012-6582-0.

[57] V.A.C. Haanappel, M.F. Stroosnijder, The effect of ion implantation on the oxidation behaviour of TiAl-based intermetallic alloys at $900{ }^{\circ} \mathrm{C}$, Surf. Coatings Technol. 105 (1998) 147-154, https://doi.org/10.1016/S0257-8972(98)00472-1.

[58] J.M. Rakowski, F.S. Pettit, G.H. Meier, F. Dettenwanger, E. Schumann, M. Ruhle, The effect of nitrogen on the oxidation of $\gamma$-TiAl, Scr. Metall. Mater. 33 (1995) 997-1003, https://doi.org/10.1016/0956-716X(95)00312-J.

[59] A. Zeller, F. Dettenwanger, M. Schötze, Influence of water vapour on the oxidation behaviour of titanium aluminides, Intermetallics 10 (2002) 59-72, https://doi.org/ 10.1016/S0966-9795(01)00104-2.

[60] A. Donchev, H.E. Zschau, M. Schütze, The halogen effect for improving the oxidation resistance of TiAl-alloys, Mater. High Temp. 22 (2005) 309-314, https:// doi.org/10.1179/mht.2005.035.

[61] B. Zhao, J. Wu, J. Sun, B. Tu, F. Wang, Effect of nitridation on the oxidation behavior of TiAl-based intermetallic alloys, Intermetallics 9 (2001) 697-703, https://doi.org/10.1016/S0966-9795(01)00054-1.

[62] T. Ihara, M. Miyoshi, Y. Iriyama, O. Matsumoto, S. Sugihara, Visible-light-active titanium oxide photocatalyst realized by an oxygen-deficient structure and by nitrogen doping, Appl. Catal. B Environ. 42 (2003) 403-409, https://doi.org/ 10.1016/S0926-3373(02)00269-2.

[63] M. Wittmer, J. Noser, H. Melchior, Oxidation kinetics of TiN thin films, J. Appl. Phys. 52 (1981) 6659-6664, https://doi.org/10.1063/1.328659.

[64] U. Hornauer, E. Richter, E. Wieser, W. Möller, G. Schumacher, C. Lang, M. Schütze, Improvement of the high temperature oxidation resistance of Ti50Al via ionimplantation, Nucl. Instr. Methods Phys. Res. Sect. B Beam Interact. Mater. Atoms 148 (1999) 858-862, https://doi.org/10.1016/S0168-583X(98)00820-9.

[65] K. Fujita, Research and development of oxidation, wear and corrosion resistant materials at high temperature by surface modification using ion processing, Surf. Coatings Technol. 196 (2005) 139-144, https://doi.org/10.1016/j.

surfcoat.2004.08.092. 